\title{
Developments in perioperative management: The yin to the yang of congenital heart surgery
}

Nicolle Ceneri, BSc, ${ }^{\mathrm{a}}$ Manan Desai, MD, ${ }^{\mathrm{b}}$ and Can Yerebakan, $\mathrm{MD}^{\mathrm{a}}$

Excellence in perioperative management and surgical technique together have led to a dramatic increase in the number of patients living with congenital heart disease (CHD) in the current era. Worldwide, the CHD community has been working to refine and perfect the perioperative management, which complements surgical repair. New developments in this area hold the key to success in advancing the field to an era of precision medicine and improving outcome parameters, such as the length of intensive care unit and hospital stay, as well as the quality of life in these patients.

The past year was marred by the pandemic due to rapid spread of severe acute respiratory syndrome coronavirus 2 around the globe. There was a sudden need for a set of guidelines to prioritize allocation of resources, which were strained because of the unprecedented crises. A multicenter group led by Stephens and colleagues ${ }^{1}$ published a set of guidelines enabling the fraternity with strategies for crisis management during the public health emergency brought by Coronavirus Disease 2019. This article serves as a cornerstone for CHD centers worldwide as the pandemic persists with no definite end in sight and continues to put our workforce to the test.

In addition to perioperative technological advancements, implementation of innovative care management strategies is another potential solution to improve patient outcomes. The Boston group has to be commended for their "Herculean effort" to derive and implement an Enhanced Recovery. After Surgery program aimed to accomplish such. ${ }^{2}$ Although their published reduction in mechanical ventilation time (7.6 vs 8.2 hours) and intensive care unit length of stay ( 1.12 vs 1.28 days) over the 5-month study period is of limited clinical significance, their program provides a multidisciplinary framework that serves as a perfect starting point for other centers to learn from and build upon. ${ }^{3-5}$

There has been a recent explosion of interest in applying our newfound knowledge of micro-RNAs in CHD. ${ }^{6}$ This

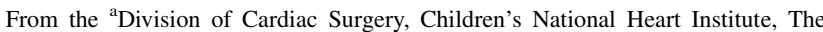
George Washington University School of Medicine and Health Sciences, Washington, DC; and 'Department of Cardiothoracic Surgery, Lucile Packard Children's Hospital, Stanford University, Palo Alto, Calif.

Received for publication May 8, 2021; revisions received May 8, 2021; accepted for publication May 10, 2021; available ahead of print May 23, 2021.

Address for reprints: Can Yerebakan, MD, Cardiovascular Surgery, Children's National Hospital, The George Washington University School of Medicine and Health Sciences, 111 Michigan Ave NW, Washington, DC 20010 (E-mail: canyerebakan@hotmail.com).

J Thorac Cardiovasc Surg 2021;162:432-4 0022-5223/\$36.00

Copyright $₫ 2021$ Published by Elsevier Inc. on behalf of The American Association for Thoracic Surgery

https://doi.org/10.1016/j.jtcvs.2021.05.027

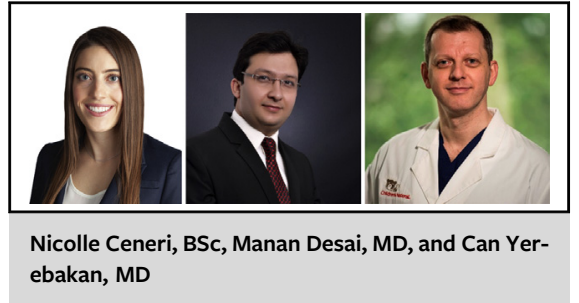

CENTRAL MESSAGE

The purpose of this review is to highlight new developments in perioperative management of CHD from the American Association for Thoracic Surgery journals and beyond in the year 2020.

year, Stoica and colleagues ${ }^{7}$ reported their findings in an attempt to discover a micro-RNA as a biomarker of cellular injury. In their study of 199 pediatric cardiac surgery patients, they demonstrate a dramatic postoperative increase in micro-RNA-1-3p (miR-1) from baseline, which was compounded by aortic crossclamp time and positively correlated with intensive care unit length of stay, postoperative occurrence of severe cardiac events, cardiovascular support (vasoactive-inotrope score), and ventilatory support (ventilation index). ${ }^{7}$ Their findings are compelling because they establish miR-1 as a clinically relevant novel biomarker of cardiovascular cellular injury for children undergoing congenital heart surgery. ${ }^{8}$ Congenital surgeons are in dire need of a reliable biomarker to monitor for postcardiac surgery ischemia related to coronary issues. Because conventional markers of myocardial ischemia, such as troponins, are increased after cardiac surgery and stay persistently elevated in the postoperative period, there is a particular need for a biomarkers, which potentially can detect subtle coronary ischemia. We wonder if miR-1 may fill this lacunae.

It is well known that patients with CHD are at increased risk of a developmental disability, with a significant proportion of patients with complex CHD sustaining brain injury during their treatment. ${ }^{9}$ The study by Cheng and colleagues ${ }^{10}$ aims to uncover new opportunities to further elucidate the role of monitoring perioperative hemodynamics and oxygen metabolism using near-infrared spectroscopy technology. They focused on oxygen extraction in different congenital 
defects such as transposition of great arteries and single ventricle and biventricular repairs in perioperative period. Whether or not applications of this technology can serve as tools for prognostication of neurologic outcomes in the short or long term is a question for future studies.

In a specialty that accrues a tremendous amount of cost and resources, careful inspection of where costs can be cut without compromising quality is of particular interest. The use of transdiaphragmatic tunneled Broviac catheters placed by the cardiac surgeon for postoperative central venous access that can remain in place until discharge, in lieu of the traditional, oftentimes multiple, percutaneous indwelling central catheters, is one inventive, cost-effective solution pioneered by the group at Vanderbilt. ${ }^{11}$ Patients undergoing single-ventricle palliation in particular may get even more bang for their buck with this method, as reliable access during the tenuous period after stage I repair can be lifesaving, and the risk of venous thrombosis from percutaneous indwelling central catheter lines can limit or compromise stage II repair. ${ }^{12}$ Chung and colleagues ${ }^{13}$ have introduced a revolutionary wireless vital signs monitoring system that although in theory likely would bear a higher sticker price boasts the potential for invaluable benefits by facilitating therapeutic skin-to-skin contact between neonates and parents during the perioperative phase. This technology has been touted by colleagues because if used in conjunction with machine learning and artificial intelligence, it can accelerate progression to an era of personalized medicine and be exploited to support clinical decision-making and risk stratification, predict adverse events, improve outcomes, and subsequently decrease overall healthcare costs. ${ }^{14}$

We have reached a remarkable milestone in that the longterm outcomes of patients with CHD are such that they are living into adulthood. The Toronto group has seized the opportunity to impact this unique population and this year contributed a risk prediction tool specifically for adult patients with CHD undergoing heart surgery. In their cohort of 784 adult patients with CHD, they identify Mayo EndStage Liver Disease modified score, cognitive impairment, 3 or more chest wall incisions, body mass index $\left(<20 \mathrm{~kg} / \mathrm{m}^{2}\right.$ or $>28 \mathrm{~kg} / \mathrm{m}^{2}$ ), and cardiac anatomic category as predictors of composite adverse outcome. ${ }^{15}$ Further, 1-year mortality of at worst $6.1 \%(40 / 657)$ was predicted by anticoagulation, Mayo End-Stage Liver Disease modified score, and anatomic category. ${ }^{15}$ This tool not only helps inform clinical decision-making but also emphasizes the multidisciplinary collaboration required by these patients in the perioperative period.

In light of the diversity of studies presented here, taken together these developments indicate that as a field, we have only just begun to scratch the surface of the potential avenues available to enhance the perioperative management of CHD. Perioperative management is the complementary force of the surgeon's scalpel. If we remain rooted in this ying and yang, our ability to improve the outcomes and livelihood of patients undergoing congenital heart surgery will break all barriers.

\section{Conflict of Interest Statement}

The authors reported no conflicts of interest.

The Journal policy requires editors and reviewers to disclose conflicts of interest and to decline handling or reviewing manuscripts for which they may have a conflict of interest. The editors and reviewers of this article have no conflicts of interest.

\section{References}

1. Stephens EH, Dearani JA, Guleserian KJ, Overman DM, Tweddell JS, Backer CL, et al. COVID-19: crisis management in congenital heart surgery. $J$ Thorac Cardiovasc Surg. 2020;160:522-8.

2. Romano JC. Commentary: the art of medicine versus paint by numbers. J Thorac Cardiovasc Surg. 2020;160:1323-4.

3. Roy N, Parra MF, Brown ML, Sleeper LA, Nathan M, Sefton BA, et al. Initial experience introducing an enhanced recovery program in congenital cardiac surgery. J Thorac Cardiovasc Surg. 2020;160:1313-21.e5.

4. Zhu A, Andersen ND, Allareddy V. Commentary: enhanced recovery program after congenital heart surgery: promising baby steps. J Thorac Cardiovasc Surg. 2020;160:1322-3.

5. Karamlou T, Najm HK, Latifi S, Sing-Si M. Commentary: false start-offense: premature data may cost more than five yards. J Thorac Cardiovasc Surg. 2020;160:1324-6.

6. Smith T, Rajakaruna C, Caputo M, Emanueli C. MicroRNAs in congenital heart disease. Ann Transl Med. 2015;3:333.

7. Stoica SC, Dorobantu DM, Vardeu A, Biglino G, Ford KL, Bruno DV, et al. MicroRNAs as potential biomarkers in congenital heart surgery. J Thorac Cardiovasc Surg. 2020;159:1532-40.e7.

8. Hobbs R, Si MS. Commentary: using microRNAs as biomarkers in pediatric cardiac surgery. J Thorac Cardiovasc Surg. 2020;159:1541-2.

9. Marino BS, Lipkin PH, Newburger JW, Peacock G, Gerdes M, Gaynor JW, et al. Neurodevelopmental outcomes in children with congenital heart disease: evaluation and management: a scientific statement from the American Heart Association. Circulation. 2012;126:1143-72.

10. Cheng HH, Ferradal SL, Vyas R, Wigmore D, McDavitt E, Soul JS, et al. Abnormalities in cerebral hemodynamics and changes with surgical intervention in neonates with congenital heart disease. J Thorac Cardiovasc Surg. 2020;159: 2012-21.

11. Ghani MOA, Raees MA, Tang AR, Anandan D, Shannon CN, Bichell DP. Transdiaphragmatic tunneled Broviac catheters: cost-effective perioperative central venous access in infants undergoing cardiac surgery. J Thorac Cardiovasc Surg. 2020;160:1559-66.

12. Kavarana MN. Commentary: transdiaphragmatic tunneled Broviac catheters: how small ripples can make big waves. J Thorac Cardiovasc Surg. 2020;160:1568-9.

13. Chung HU, Kim BH, Lee JY, Lee J, Xie Z, Ibler EM, et al. Binodal, wireless epidermal electronic systems with in-sensor analytics for neonatal intensive care. Science. 2019;363:eaau0780.

14. Kalfa D, Agrawal S, Goldshtrom N, LaPar D, Bacha E. Wireless monitoring and artificial intelligence: a bright future in cardiothoracic surgery. J Thorac Cardiovasc Surg. 2020;160:809-12.

15. Lei EL, Ladha K, Mueller B, Roche L, Rao V, Hickey E, et al. Noncardiac determinants of death and intensive care morbidity in adult congenital heart disease surgery. J Thorac Cardiovasc Surg. 2020;159:2407-15.e2.

Key Words: perioperative management, congenital heart disease, developments 


\section{Developments in Perioperative Management: Recent Article from AATS Journals}

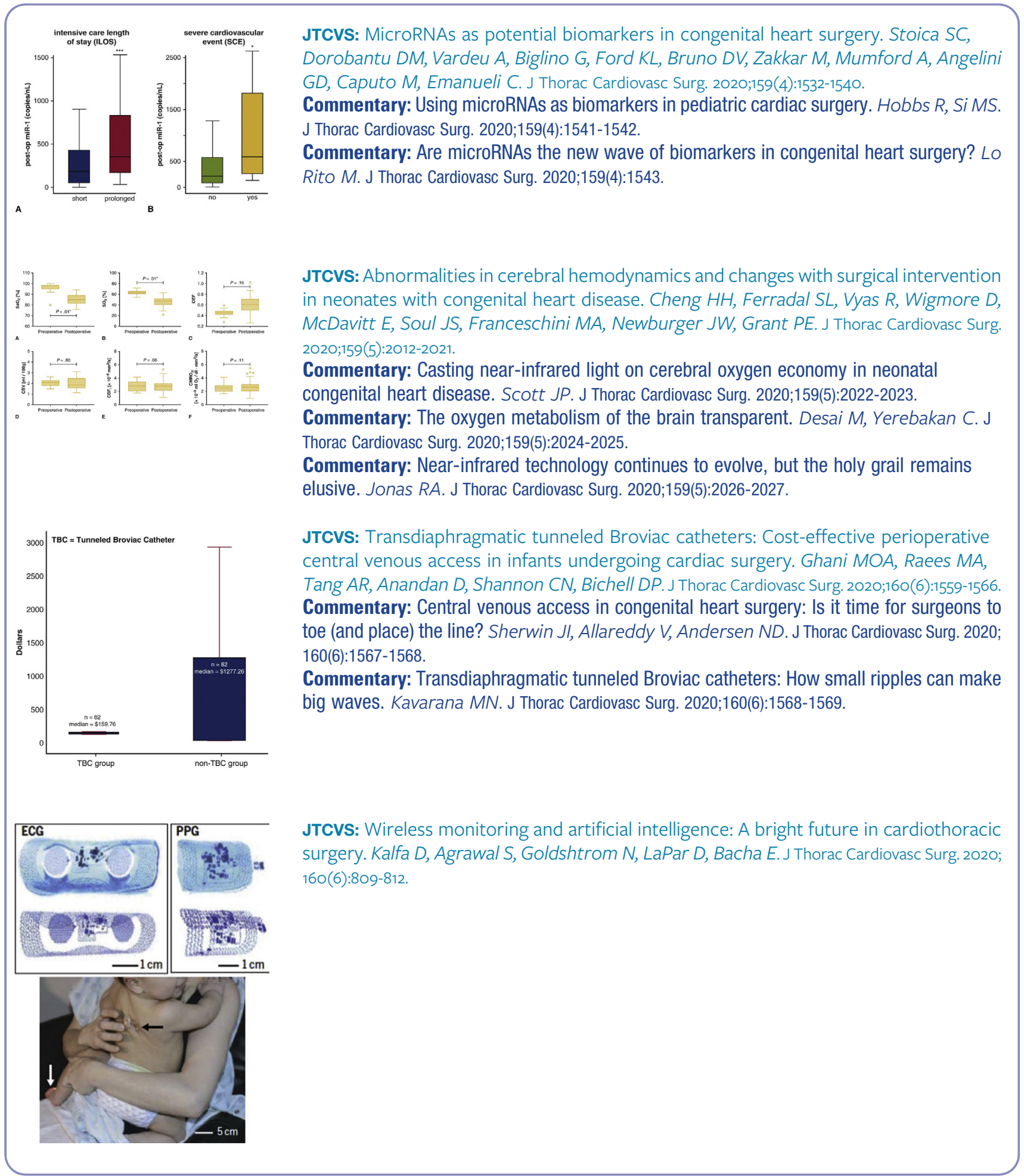

